\title{
Molecular analysis of the PHO81 gene of Saccharomyces cerevisiae
}

\author{
Caretha L.Creasy ${ }^{1,2}$, Stephen L.Madden ${ }^{2,+}$ and Lawrence W.Bergman ${ }^{1, *}$ \\ ${ }^{1}$ Department of Microbiology and Immunology, Hahnemann University School of Medicine, \\ Philadelphia, PA 19102 and ${ }^{2}$ Department of Biological Sciences, Ohio University, Athens, \\ $\mathrm{OH}$ 45701, USA
}

Received October 5, 1992; Revised and Accepted March 5, 1993

\begin{abstract}
The PHO81 gene product is a positive regulatory factor required for the synthesis of the phosphate repressible acid phosphatase (encoded by the PHO5 gene) in Saccharomyces cerevisiae. Genetic analysis has suggested that PHO81 may be the signal acceptor molecule; however, the biochemical function of the PHO81 gene product is not known. We have cloned the PHO81 gene and sequenced the promoter. A PHO81-LacZ fusion was shown to be a valid reporter since its expression is regulated by the level of inorganic phosphate and is controlled by the same regulatory factors that regulate PHO5 expression. To elucidate the mechanism by which PHO81 functions, we have isolated and cloned dominant mutations in the PHO81 gene which confer constitutive synthesis of acid phosphatase. We have demonstrated that overexpression of the negative regulatory factor, PHO80, but not the negative regulatory factor PHO85, partially blocks the constitutive acid phosphatase synthesis in a strain containing a dominant constitutive allele of PHO81. This suggests that PHO81 may function by interacting with $\mathrm{PHO} 80$ or that these molecules compete for the same target.
\end{abstract}

\section{INTRODUCTION}

Acid phosphatase in Saccharomyces cerevisiae functions to scavenge inorganic phosphate $\left(\mathrm{P}_{\mathrm{i}}\right)$ from the environment. The repressible form of this molecule is encoded by several genes, but the primary gene product is derived from the PHO5 gene (1-4). Expression of the PHO5 gene is tightly regulated.That is, during periods of high $\mathrm{P}_{\mathrm{i}}$, expression of PHO5 is repressed while upon shifting the cells to low inorganic phosphate PHO5 expression is rapidly derepressed $(5,6)$.

Extensive genetic analysis indicates that the PHO5 gene is regulated by at least 5 regulatory factors $(7-9)$. When $P_{i}$ levels are limiting, the two positive regulators, $\mathrm{PHO} 4$ and $\mathrm{PHO} 2$, activate transcription by binding to the PHO5 upstream activator sequences (UAS) (10). PHO4 appears to be a classic activator in that it contains an acidic domain responsible for activation and a distinct helix-loop-helix domain required for DNA binding (11). The functional regions of $\mathrm{PHO} 2$ have not been mapped, but the molecule contains a homeodomain (12). In addition, $\mathrm{PHO} 2$ has been implicated in the expression of other genes (13-15). Under repressing conditions (high $\mathrm{P}_{\mathrm{i}}$ ) the negative regulators, PHO80 and PHO85, block activation (16). It is believed that PHO80 directly interacts with $\mathrm{PHO} 4$ or competes with $\mathrm{PHO} 4$ for DNA binding. It is not clear where in the regulatory scheme PHO85 functions, but analysis of its coding sequence indicates that it shares homology with several known protein kinases, and recent experiments have shown that when overexpressed, in vivo, PHO85 can phosphorylate casein in vitro $(17-19)$. The fifth regulator, PHO81, has been implicated as the mediator molecule. That is, it may act on the negative regulatory factors thereby blocking their actions. PHO81 is not believed to act via an association with $\mathrm{PHO} 4$ and/or $\mathrm{PHO} 2$ since genetic studies show PHO81 acting hypostatic to both PHO80 and PHO85 (7). Unlike the other known regulators of acid phosphatase, PHO81 appears to be regulated at the level of transcription by the level of $P_{i}$ in the extracellular environment (20). Recently, the structural region of the PHO81 gene has been cloned and found to encode a protein of 1177 amino acids with no significant homologies to any other protein (21).

In this paper, we have cloned the PHO81 gene including its promoter and examined the regulation of PHO81 mRNA production. We have isolated and analyzed dominant constitutive mutations in the PHO81 gene and find that these mutants have increased expression of PHO81, but expression is still dependent on $P_{i}$ levels. Analysis of each mutant indicates that single amino acid changes clustered in the amino-terminal portion of the protein give rise to the mutant phenotype. In addition, we find that overexpression of PHO80, but not PHO85, partially represses the mutant phenotype.

\footnotetext{
* To whom correspondence should be addressed

+ Present address: The Wistar Institute, University of Pennsylvania, Philadelphia, PA 19104, USA
} 


\section{MATERIALS AND METHODS}

\section{Strains and media}

Yeast strains used in this work are listed in Table 1. The strain, CY34, was made by first inserting HIS3 as a $1.9 \mathrm{~kb}$ BamHI fragment into the 5' BglII site of PHO81. The resulting BamHI fragment containing HIS3 flanked by PHO81 sequences was then used to transform strain YP198. His ${ }^{+}$transformants were isolated, and the presence of the pho81::HIS3 disruption was confirmed by Southern analysis. Cells were grown in either YPD ( $10 \mathrm{~g} / \mathrm{L}$ yeast extract, $20 \mathrm{~g} / \mathrm{L}$ bactopeptone and $20 \mathrm{~g} / \mathrm{L}$ dextrose) or minimal media $(6.7 \mathrm{~g} / \mathrm{L}$ yeast nitrogen base lacking amino acids and $20 \mathrm{~g} / \mathrm{L}$ dextrose, supplemented with $20 \mu \mathrm{g} / \mathrm{ml}$ of the appropriate amino acids or bases). Transformations of yeast cells were performed using the lithium acetate procedure of Ito et al. (22).

\section{Plasmids}

The plasmid p947-270T, a derivative of pBM947 (23), contains the 268 bp BamHI-ClaI fragment from the PHO5 gene cloned upstream of the GAL1 promoter which, in turn, is fused to the structural sequences of HIS3. The PHO5 fragment described contains sequences sufficient to direct the synthesis of HIS3 in a phosphate-dependent manner. Additionally, immediately upstream of the PHO5 fragment we have placed an approximately 600 bp fragment containing the 3 '-end of the yeast CYC1 gene to prevent read-through from an endogenous plasmid promoter. The plasmids, pBM150-80, pBM150-85, and pBM150-81, are pBM150 (24) based plasmids in which PHO80, PHO85 and PHO81 have been placed under control of the GAL1 promoter.

\section{Cloning the PHO81 gene}

Oligonucleotide primers corresponding to bases -5 to +16 and bases +1330 to +1311 of the PHO81 coding sequence (21) were synthesized and used to amplify a portion of the gene from genomic DNA isolated from the yeast strain, YP198, using the polymerase chain reaction essentially as described by Innis and Gelfand (25). The product was isolated from an agarose gel and purified using Geneclean (Bio101). This $1.3 \mathrm{~kb}$ fragment was labeled with [ $\left.{ }^{32} \mathrm{P}\right] \mathrm{dATP}$ with a random priming kit (Stratagene) and used to screen a YCP50 yeast library (26). Positives were selected for plasmid isolation and restriction analysis performed.

Isolation, cloning and mapping PHO81 constitutive mutants Initailly $4 \times 10^{8}$ cells (strain YNN281/282 containing plasmid p947-270T) were collected, washed and one aliquot was treated with ethylmethylsulfonate (EMS). The cells (21\% survival for the EMS-treated cells as compared to the untreated control) were plated on plates lacking uracil (high $\mathrm{Pi}$ ) and grown for 3 days. The cells were then replica plated to media lacking both uracil and histidine (high $\mathrm{Pi}$ ) and grown for 5 days. Only 12 of the $137 \mathrm{His}^{+}$colonies also constitutively expressed acid phosphatase, suggesting the majority were plasmid-borne defects. Five of the 12 remaining colonies were $\mathrm{spo}^{-}$and were discarded. The remaining 7 colonies were analyzed.

To create a constitutive PHO81 library, genomic DNA from one of the PHO81 constitutive strains, CY81-C12, was isolated and partially digested with Sau3A. The digested DNA was fractionated over a sucrose gradient and DNA in the range of 6-20 $\mathrm{kb}$ was pooled, dialyzed against TE and ethanol precipitated. This DNA was ligated into YCP50 which had been digested with BamHI and treated with calf intestinal alkaline
Table 1. Strains used in this study

\begin{tabular}{|c|c|c|}
\hline STRAIN & GENOTYPE & SOURCE: \\
\hline YP98 & $\begin{array}{l}\text { MATa ura3-52, lys2-801, ade2-10l, } \mathrm{trp} / \Delta l \\
\text { leu2 } \mathrm{l} \text {. }\end{array}$ & P. Hieter \\
\hline YPI98 & 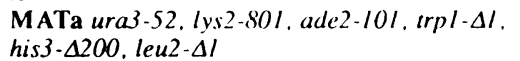 & this lab \\
\hline CY34 & 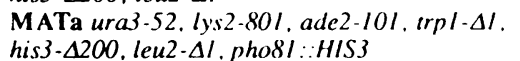 & this study \\
\hline CY25 & 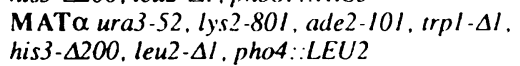 & this lab \\
\hline CY27 & 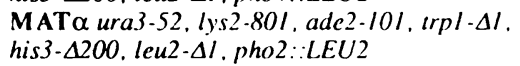 & this lab \\
\hline $\mathrm{h}-\mathrm{A}$ & 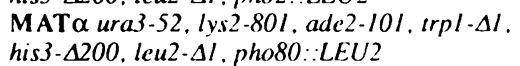 & $(28)$ \\
\hline 85TRP-A & 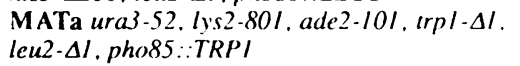 & $(32)$ \\
\hline YNN281 & 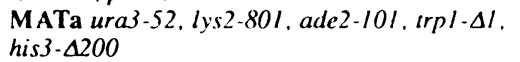 & M. Johnston \\
\hline YNN281/282 & 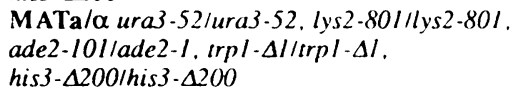 & M. Johnston \\
\hline $242-110-10$ & 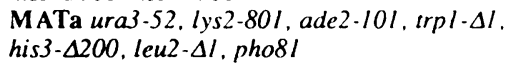 & this lab \\
\hline YAT242 & MATa phosI & R. Kramer \\
\hline
\end{tabular}

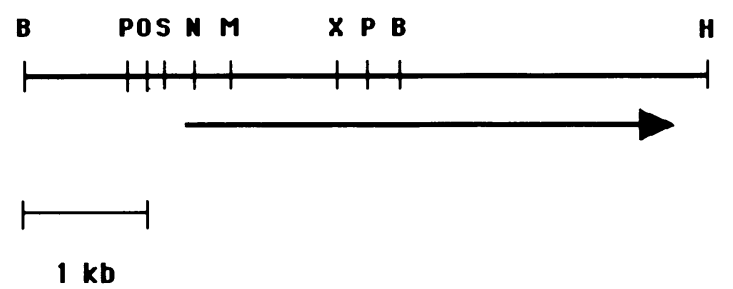

Figure 1. A Partial restriction map of the PHO81 gene. B, BamHI; O, XhoI; P, PstI, S, SpeI; N, BstNI; M, MscI; X, XbaI; H, HindIII; A, HpaII. The arrow indicates the approximate location of the coding region.

phosphatase. E.coli strain DH5 $\alpha$ was transformed with the constitutive PHO81 library, colony hybridization performed and positives subjected to restriction analysis. To map the region of the mutation, the $2.9 \mathrm{~kb}$ BamHI fragment was purified and cloned into $315-81 \mathrm{BP}$, a centromeric plasmid containing LEU2 as a selectable marker (27) and the wild type PHO81 gene from the internal BamHI site to the 3' Hpall site. The resulting hybrid plasmid, 315-81C12 was used to transform strain CY34. To further localize the site of the mutation SpeI (one site is within the vector, 5' to the PHO81 insert) or MscI-ApaI (the ApaI site is within the vector, $3^{\prime}$ of the PHO81 insert) fragments from 315-81WT and 315-81C12 were interchanged to generate several hybrid plasmids and analyzed as above.

Oligonucleotide primers corresponding to bases of the PHO81 gene were synthesized and used to amplify genomic DNA of each of the remaining mutants. Reaction conditions were as described above. The purified fragments were digested with XhoI and BglII. Each fragment was then substituted for the wild type sequence in p18-81Bam. This plasmid contains the 5' end of PHO81 as a $2.9 \mathrm{~kb}$ BamHI fragment. BamHI fragments were then cloned into $315-81 \mathrm{BP}$. These hybrid plasmids were used to transform CY34 and acid phosphatase assays performed.

\section{Northern analysis}

Total RNA was isolated and blots performed essentially as described previously (28). To determine the amount of PHO81 


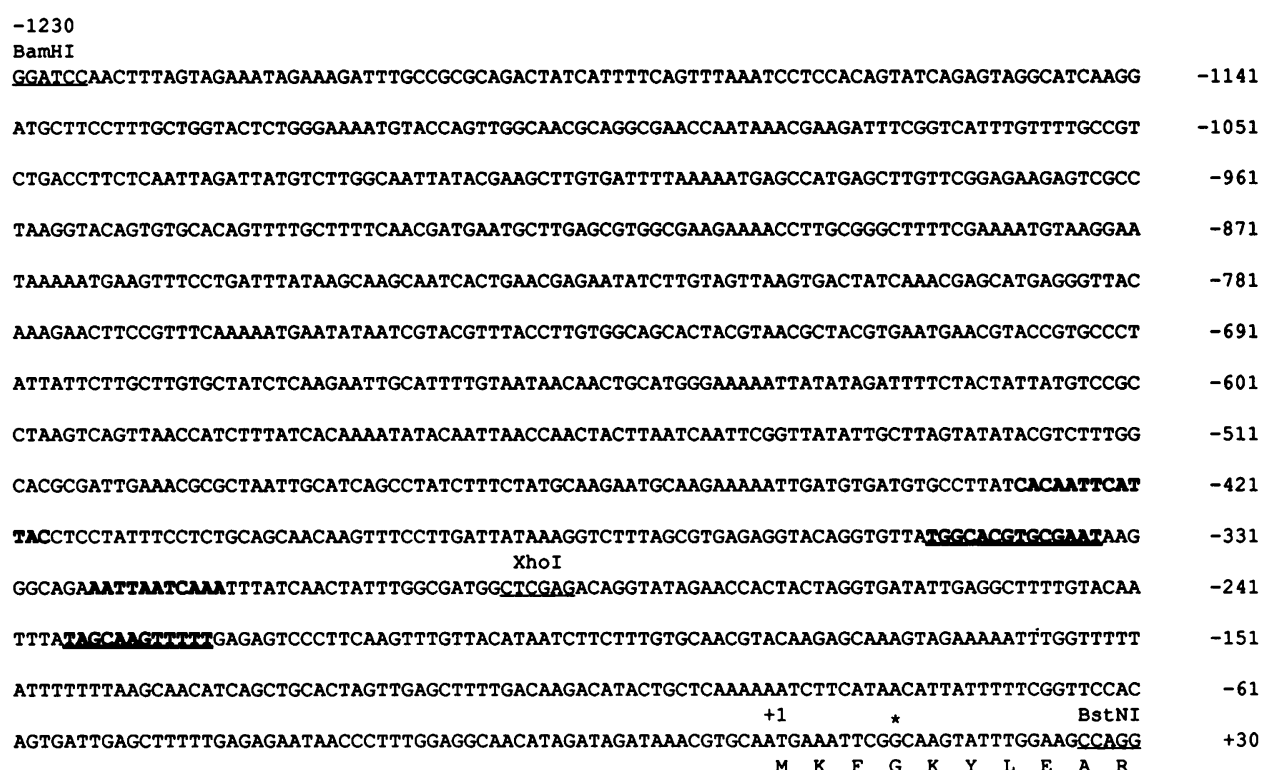

Figure 2. Sequence of the PHO81 promoter. The BamHI-BstNI fragment was sequenced and potentially important cis-elements identified via a homology search. Potential PHO2 and PHO4 binding sites are shown in bold and underlined bold, respectively. Restriction sites discussed in the text are underlined. +1 indicates the site of translation initiation and the deduced amino acid sequence is indicated as a one-letter code on the lower line. The asterisk indicates the site of the mutation in the PHO81 gene isolated from strain CY81-C12.

mRNA obtained from the GAL1-PHO81 fusion grown under inducing conditions, different amounts of RNA from a strain containing this fusion plasmid were compared to a known amount of RNA isolated from YNN281 grown in low phosphate media. The PHO81 probe was a $1.1 \mathrm{~kb}{ }^{32} \mathrm{P}$ labeled anti-sense RNA generated by in vitro transcription of the BamHI-HindIII fragment. A $3.4 \mathrm{~kb}$ EcoRI fragment from the yeast clathrin gene (a gift from Dr S. Lemmon) was labeled with [ $\left.{ }^{32} \mathrm{P}\right] \mathrm{dCTP}$ by random priming (Stratagene) and used to normalize the PHO81 signal.

\section{Enzyme assays}

A $1.2 \mathrm{~kb}$ BamHI-BstNI ( $3^{\prime}$ end at amino acid 9 of the PHO81 gene) fragment was isolated from wild type PHO81 and the constitutive mutant, C12. These fragments were blunt-ended using the Klenow fragment of DNA polymerase I and cloned into the SmaI site of YEP357R, a LacZ fusion vector (29). In frame fusions were selected by their blue appearance on X-gal plates. CEN3 was then inserted as a $900 \mathrm{bp}$ BamHI fragment. These new constructs, C357R-81WT and C357R-81C12, were then used to transform YP98, CY25, CY27, h-A, 85TRP-A and CY34 (Table 1). A $1.7 \mathrm{~kb}$ BamHI-BglII fragment ( ${ }^{\prime}$ ' end at amino acid 157 of the PHO81 gene) was isolated from wild type PHO81 and the constitutive mutant, C3. This fragment was cloned into the BamHI site of yEP357 and in frame fusions selected. These latter fusion were used to transform strains 85TRP-A and YNN281. Acid phosphatase and $\beta$-galactosidase assays were performed as described previously (30).

\section{DNA sequence analysis}

Sequencing was performed using the Sequenase kit (United States Biochemicals) and M13 primers or oligonucleotide primers complementary to the wild type PHO81 sequence.
Table 2. The effects of regulatory mutations on expression of a PHO81-LacZ fusion

\begin{tabular}{|c|c|c|}
\hline \multirow[t]{2}{*}{ STRAIN $^{\mathrm{a}}$} & \multicolumn{2}{|c|}{ SPEC.ACTIVITY $^{b}$} \\
\hline & $\mathrm{HI} \mathrm{PO} 4$ & LO PO \\
\hline $\begin{array}{c}\text { YP98 } \\
\text { (WILD TYPE) }\end{array}$ & 15 & 25 \\
\hline $\begin{array}{c}\text { CY25 } \\
\text { (pho4::LEU2) }\end{array}$ & 5 & 4 \\
\hline $\begin{array}{c}\text { CY27 } \\
\text { (pho2::LEU2) }\end{array}$ & 7 & 5 \\
\hline $\begin{array}{c}\text { CY34 } \\
\text { (pho81::HIS3) }\end{array}$ & 5 & 4 \\
\hline $\begin{array}{c}\text { h-A } \\
\text { (pho80::LEU2) }\end{array}$ & 123 & 123 \\
\hline $\begin{array}{c}\text { 85TRP-A } \\
\text { (pho85::TRPI) }\end{array}$ & 196 & 247 \\
\hline
\end{tabular}

a The genotype of each strain listed in Table 1 .

b Units of $\beta$-galactosidase per $\mathrm{mg}$ of protein. Activity of each is an average of the specific activity found with 2 independent isolates at 2 different time points.

\section{RESULTS}

\section{Cloning and expression of the PHO81 gene}

Oligonucleotide primers corresponding to a portion of the PHO81 coding sequence (21) were used to amplify the gene from genomic DNA using the polymerase chain reaction. The amplified region was then used to screen a YCP50 yeast library (26). One isolate 


\begin{tabular}{|c|c|c|c|}
\hline PLASMID & STRUCTURE & $\begin{array}{l}\text { ACID } \\
\text { PHOSPHATASE } \\
\text { ACTIVITY }\end{array}$ & PHENOTYPE \\
\hline $315 \cdot 81 \mathrm{C} 12$ & IIIIIII & 0.285 & $\operatorname{CON}$ \\
\hline 315-81WT & & 0.087 & WT \\
\hline 315-MC12-5 & 피피 & 0.345 & CON \\
\hline 315-MC12-3 & & 0.055 & WT \\
\hline 315-SC12-5 & IIIIIII & 0.042 & WT \\
\hline $315-S C 12-3$ & & 0.136 & CON \\
\hline 315 & NO PHO81 & 0.055 & $\cdots$ \\
\hline
\end{tabular}

Figure 3. Acid phosphatase assays and a schematic representation of the hybrid plasmids used to localize the site of the constitutive mutation in CY81-C12. A solid bar represents the wild type gene and the stippled bar represents the mutant gene. Each copy of PHO81 was cloned into pRS-315, a centromeric plasmid which has LEU2 as the selectable marker. CY34, a yeast strain with a disruption in PHO81 by HIS3 was transformed with each plasmid. 315-MC12-5 and 315-MC12-3 are hybrid products derived from digesting 315-81C12 and 315-81WT with MscI and ApaI (within the vector, 3' of PHO81 insert) (see Figure 1). 315-SC12-5 and 315-SC12-3 are hybrid products derived from digesting $315-81 \mathrm{C} 12$ and 315-81WT with SpeI (one site within the vector, 5' of the PHO81 insert).

contained the entire coding region, as determined by restriction site comparison to the published sequence of the PHO81 coding region (see Figure 1). In addition, this isolate contained several kilobases upstream of the translation start site. The DNA sequence of the upstream region was determined from the BamHI site to the BstNI site (see Figure 2). Computer analysis revealed several potential homologies to $\mathrm{PHO} 4$ and $\mathrm{PHO} 2$ binding sites within the upstream region.

We examined the expression of the PHO81 gene by constructing a centromeric PHO81-LacZ fusion plasmid and transforming the plasmid into a wild type yeast strain as well as other yeast strains, each containing a disruption of an acid phosphatase regulatory gene. These results indicated that PHO81 expression is regulated in a manner analogous to PHO5 (Table 2). That is, there is a derepression of PHO81 transcription under low phosphate conditions. Expression of PHO81 requires PHO4, PHO2 and PHO81, and without a functional PHO80 or PHO85 molecule full derepression occurs. There is an approximately 2 -fold increase in the level of $\beta$-galactosidase under low $\mathrm{P}_{\mathrm{i}}$ in a wild type cell (YP98); however, this increase in expression is far less than what is observed for PHO5 expression (data not shown).

\section{Selection of mutants}

A selection scheme was developed and utilized such that constitutive mutations within the regulatory genes of acid phosphatase could be detected. A wild type diploid strain (YNN281/282), was transformed with plasmid p947-270T, a derivative of pBM947 (a gift from Dr Mark Johnston) in which we have placed the HIS3 gene under the control of the PHO5 UAS. This plasmid contains a centromere and has URA3 as an additional selectable marker. A transformant was grown in the absence of uracil and mutagenized with ethylmethyl sulfonate. The ura $^{+}$colonies were replica-plated to plates lacking histidine but containing high phosphate. If a mutation arose, resulting in constitutive synthesis of HIS3 the cell would grow in the absence of histidine. These colonies were picked and screened for
Table 3. A summary of PHO81 constitutive mutants

\begin{tabular}{|c|c|c|c|c|}
\hline MUTANT & BASEPAIR & $\begin{array}{l}\text { BASE PAIR } \\
\text { CHANGE }\end{array}$ & $\begin{array}{l}\text { AMINO ACID } \\
\text { RESIDUE }\end{array}$ & $\begin{array}{l}\text { AMINO ACII } \\
\text { CNANGEE }\end{array}$ \\
\hline $\mathrm{C}_{2}$ & +11 & $G>A$ & 4 & GLY TO ASP \\
\hline $\mathrm{C} 21, \mathrm{C} 93$ & +235 & G>A & 79 & GLUTOLYS \\
\hline C3.C4. C95. C96 & +439 & $\mathrm{G}>\mathrm{A}$ & 147 & GI.Y TO ARG \\
\hline
\end{tabular}

constitutive synthesis of acid phosphatase (as demonstrated by blue appearance on X-P plates). Potential mutants were sporulated, dissected and haploids constitutively producing acid phosphatase were isolated for further analysis. Seven independent mutants were isolated. Mating and dissection analysis indicated that all mutants were within the same complementation group or tightly linked. However, with the exception of the structural genes for acid phosphatase, PHO5 and PHO3, none of the previously described genes involved in this system have been shown to be genetically linked. Mating of each mutant to a wild type cell indicated that the mutations were dominant. One mutant was mated to known acid phosphatase mutants, and found to exclusively segregate $2: 2$ with a pho81 nonderepressible mutant (strain, 242-110-10, Table 1) indicating that the mutation resided at the PHO81 locus.

\section{Cloning and mapping the constitutive mutations}

Sau3A digested genomic DNA from one mutant (CY81-C12) was used to construct a YCP50 library. Approximately 50,000 E.coli transformants were screened with a $1.7 \mathrm{~kb}$ PstI fragment from PHO81 as the probe (see Figure 1). Several positives were found, but restriction analysis indicated that all were identical and the entire gene had been cloned (insert approximately $6.5 \mathrm{~kb}$ ). To map the mutation, the $2.9 \mathrm{~kb}$ BamHI (see Figure 1) fragment was cloned into 315-81BP which is centromeric, contains LEU2 as the selectable marker and contains the remaining $3^{\prime}$ end of the wild type PHO81 gene. This hybrid plasmid (315-81C12) was used to transform the yeast strain CY34. Acid phosphatase levels (Figure 3 ) indicated that the mutation causing constitutive synthesis of acid phosphatase was within the $2.9 \mathrm{~kb}$ BamHI fragment. Additional subcloning was then utilized to further localize the site of the mutation (see Materials and Methods for details). The results from acid phosphatase assays of these subclones indicated that the mutation mapped between the SpeI and the MscI site (Figure 3). DNA sequence analysis within this region revealed a single base pair change $\mathrm{a} G$ to an $\mathrm{A}$ at nucleotide +11 (see Figure 2 and Table 3). This mutation changes amino acid 4 , a glycine to an aspartic acid.

Rather than clone the entire PHO81 gene from each of the remaining 6 mutant strains, the polymerase chain reaction was utilized to amplify a portion of the gene. The region between the XhoI and BglII sites (nucleotides -290 to +472 ) was chosen for amplification. This region was selected for two reasons. First, it contains much of the promoter, and second, it encompasses the site of the first mutation. PCR products were digested with XhoI and BgIII and used to replace the corresponding wild type sequence in p18-81Bam which contains the wild type $2.9 \mathrm{~kb}$ BamHI fragment. The hybrid BamHI fragments were then inserted into 315-81BP (described above) and hybrid plasmids used to transform strain CY34. Acid phosphatase assays indicated 


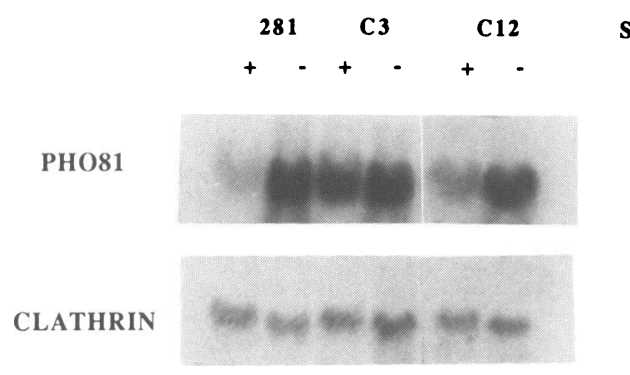

STRAIN

$\mathbf{P}$

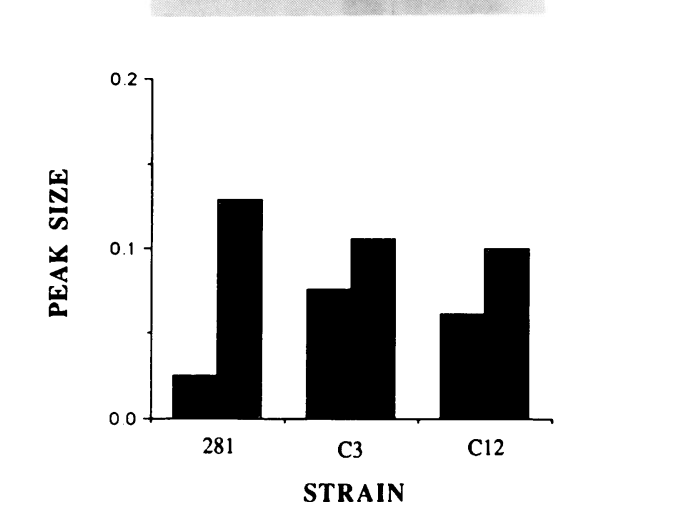

Figure 4. Northern blot of wild type and constitutive yeast strains. A wild type yeast strain (YNN281) and 2 dominant constitutive mutants (CY81-C12 and CY81-C3) were grown in rich media in the presence of high $(+)$ or low (-) phosphate. RNA was isolated from each strain and $60 \mu \mathrm{g}$ of total RNA separated on a denaturing agarose gel. The RNA was transferred to nitrocellulose and probed with a 321P-labeled anti-sense RNA derived from a BamHI-HindIII fragment (Figure 1). The same filter was then reprobed with a $3.4 \mathrm{~kb}$ EcoRI fragment from clathrin (a gift from Dr Sandy Lemmon) as a standard. A summary of the blot is shown below. Densitometric scans of the PHO81 signal were normalized against the clathrin signal.The solid and stippled bars represent mRNA levels in high $P_{i}$ and low $P_{i}$ levels, respectively.

that the mutations resided in this region (data not shown). In 4 of the mutants, the glycine at amino acid 147 was changed to an arginine, and in 2 of the mutants, the glutamic acid at amino acid 79 was changed to a lysine (Table 3 ).

To examine expression of the constitutive alleles, northern analysis was performed on mutants, CY81-C3 and CY81-C12, and a wild type yeast strain, YNN281. As shown in figure 4, both mutants were expressed at approximately 3-fold higher levels than wild type under repressing conditions (high $P_{i}$ ), and at slightly lower levels under derepressing (low $\mathrm{P}_{\mathrm{i}}$ ) conditions, but each mutant still responded to phosphate signals.

The affect of these mutations was further examined by constructing constitutive PHO81-LacZ fusions. The PHO81-C12-LacZ fusion was constructed exactly as the previous wild type LacZ fusion (described above) containing the entire PHO81 promoter and the first 9 amino acids of PHO81. The only difference between this mutant and the wild type fusion is the single base pair change at +11 . To examine the mutation at amino acid 147, LacZ fusions were constructed with both mutant, $\mathrm{C} 3$ and wild type sequences such that the entire promoter and the first 157 amino acids were present. $\beta$-galactosidase levels for the PHO81-C12 fusion were found to be approximately 2 -fold higher than that of the wild type fusion in a variety of genetic backgrounds (Table 4). In addition, this constitutive fusion responded to $P_{i}$ levels, consistent with the data from the Northern blot (see Figure 4). In contrast, the PHO81-C3 fusion functioned essentially like the comparable wild type fusion $(81 \mathrm{G})$
Table 4. The effect of an amino acid change at residue 4 on expression of a PHO81-LacZ fusion

\begin{tabular}{|c|c|c|c|c|}
\hline \multirow[t]{2}{*}{ FUSION ${ }^{a}$} & \multirow[t]{2}{*}{ STRAIN } & \multicolumn{2}{|c|}{ SPEC. ACTIVITYC } & \multirow[t]{2}{*}{ LOW/HIGH } \\
\hline & & $\mathrm{HI} \mathrm{PO} 4$ & $\mathrm{LO} \mathrm{PO}_{4}$ & \\
\hline WT-N & $\begin{array}{c}\text { YP98 } \\
\text { (WILD TYPE) }\end{array}$ & 15 & 25 & 1.7 \\
\hline $\mathrm{Cl} 2$ & $\begin{array}{c}\text { YP98 } \\
\text { (WILD TYPE) }\end{array}$ & 25 & 51 & 2.0 \\
\hline WT-N & $\begin{array}{c}\text { CY25 } \\
\text { (pho4::LEU2) }\end{array}$ & 5 & 4. & 0.8 \\
\hline $\mathrm{C} 12$ & $\begin{array}{c}\text { CY25 } \\
\text { (pho4::LEU2) }\end{array}$ & 10 & 7 & 0.7 \\
\hline WT-N & $\begin{array}{c}\text { 85TRP-A } \\
\text { (pho85::TRP1) }\end{array}$ & 196 & 247 & 1.3 \\
\hline $\mathrm{Cl} 2$ & $\begin{array}{c}\text { 85TRP-A } \\
\text { (pho85::TRPI) }\end{array}$ & 367 & 359 & 1.0 \\
\hline WT-G & $\begin{array}{c}\text { 85TRP-A } \\
\text { (pho85::TRPI) }\end{array}$ & 70 & N.D. ${ }^{d}$ & \\
\hline $\mathrm{C} 3$ & $\begin{array}{c}\text { 85TRP-A } \\
\text { (pho85::TRP1) }\end{array}$ & 59 & N.D. ${ }^{d}$ & \\
\hline
\end{tabular}

a Fusions WT-N and C12 are centromeric and contain PHO81 sequences from the 5' BamHI site to the BstNI site (see Figures $1 \&$ 2). They are identical except for a base pair change at $+11, \mathrm{a} \mathrm{G}$ to an $\mathrm{A}$ in $\mathrm{C} 12$. This mutation changes amino acid 4 from a glycine to an aspartic acid. Fusions WT-G and C3 contain PHO81 sequences from the 5 ' BamHI to the BgllI site at +472 . They are identical except for the mutation at +439 which changes amino acid 147 from a glycine to an arginine.

b The genotype of each strain is listed in Table 1.

c Units of $\beta$-galactosidase per $\mathrm{mg}$ of protein. Activity of each is an average of the specific activity found with 2 independent isolates at 2 different time points. d Not determined.

in a strain containing a disruption of the PHO85 gene (see Table 4 ) and in a wild type cell (data not shown). The increase in $\beta$ galactosidase levels seen with the PHO81-C12 fusion can not be due to an increase in PHO81's ability to act on its target because the constitutive LacZ fusion does not produce a functional PHO81 molecule.

To determine if an increase in the amount of PHO81 is sufficient to cause derepression of acid phosphatase under high $P_{i}$ growth conditions, the wild type PHO81 gene was fused to the highly inducible GAL1 promoter. As shown in figure 5A, induction of PHO81 expression in galactose caused an approximate 5-fold increase in acid phosphatase production in a yeast strain lacking PHO81 (CY34) as compared to the same strain transformed with the vector alone. However, these levels of acid phosphatase are approximately 2-3 fold lower than that found when CY34 is transformed with wild type PHO81 grown in derepressing conditions (Figure 5A). Northern analysis indicates that there is approximately 60 times more PHO81 mRNA in the cell when PHO81 is fused to the GAL1 promoter as compared to a wild type cell grown in low $\mathrm{P}_{\mathrm{i}}$ conditions (Figure 5B); however, we do not know the level of translation of this mRNA. Because overexpression of wild type PHO81 leads to only partial derepression of acid phosphatase expression, it is likely that post-translational modifications of the PHO81 gene product occurs when there is a shift to low $P_{i}$ growth conditions. 
A

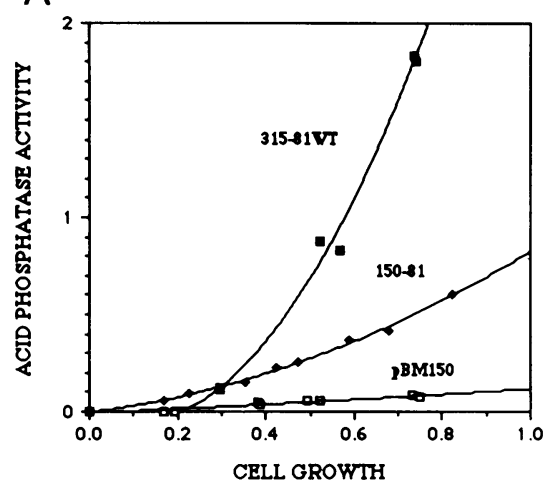

B

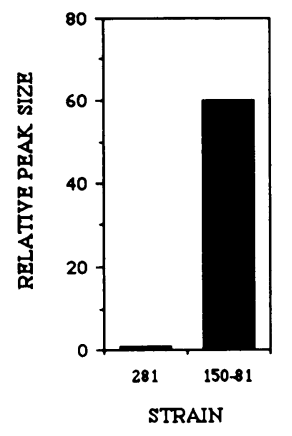

Figure 5. A. Acid phosphatase assays demonstrating the effect of overexpressing the PHO81 molecule. Strain CY34 was transformed with either pBM150-81(closed diamonds), which contains the PHO81 coding region fused to the GAL1 promoter; pBM150 (open squares), the vector alone; or 315-81WT (closed squares) a centromeric plasmid which contains the entire PHO81 gene. Two isolates from each transformation were chosen for assays. pBM150 based plasmids were grown in minimal media lacking uracil with galactose as the carbon source. 315-81WT was grown in minimal media lacking leucine with dextrose as the carbon source. Acid phosphatase activity was measured at three time points using $200 \mu$ l of cells for each assay. B. A summary of the Northern blot performed on RNA isolated from either strain CY34 transformed with pBM150-81 grown in minimal media with galactose as the carbon source, or strain $Y N N 281$ grown in low $P_{i}$ minimal growth media with dextrose as the carbon source. The PHO81 signal was normalized against the clathrin signal as in figure 4.

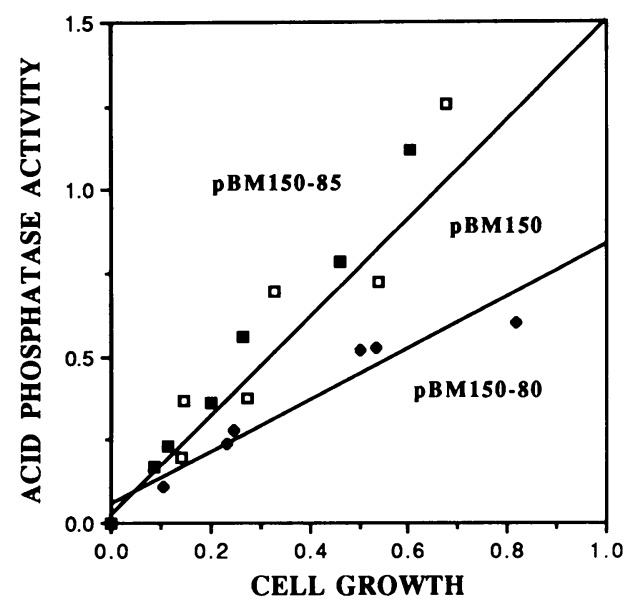

Figure 6. Acid phosphatase assays demonstrating the effect of overexpressing the PHO80 or PHO85 molecule. Strain CY81-C12 was transformed with either pBM150-80 (solid diamonds), which contains the PHO80 coding region fused to the GAL1 promoter, pBM150-85 (solid squares), which contains the PHO85 molecule fused to the GAL1 promoter, or pBM150 (open square), the vector alone. The lines for pBM150-85 and pBM-150 are identical. Two isolates from each transformation were chosen and grown in minimal media lacking uracil with galactose as the carbon source. Acid phosphatase activity was measured at three time points using $100 \mu \mathrm{l}$ of cells for each assay.

\section{Overexpression of PHO80 or PHO85}

If the PHO81 constitutive mutants either cause an increase in PHO81 concentration or increase the affinity of PHO81 for its target, then overexpressing the target molecule may cause a repression in acid phosphatase activity in a PHO81 constitutive
GENE PUTATIVE PHO4 BINDING SEQUENCE

\begin{tabular}{|c|c|c|c|}
\hline PHO81-1 & -347 & TgGCACGTGcgat & -334 \\
\hline PHO81-2 & -236 & TaGCAaGTttt & -226 \\
\hline PHO5-1 & -368 & aat TaGCACGTtttcgcat & -349 \\
\hline PHO5-2 & -260 & gcacTcaCACGTGgga & -245 \\
\hline PHO8 & -547 & atctacgtcgggcCACGTGcagcgatca & -520 \\
\hline CONSENSUS & & TNGCACGTG & \\
\hline GENE & & PUTATIVE PHO2 BINDING SEQUENCE & \\
\hline PHO81-1 & -430 & CacAATTCaTtAC & -418 \\
\hline PHO81-2 & -324 & AATTa TCAAa & -314 \\
\hline PHO5 & -277 & gaatAggcAATcTCTaAAcg & -296 \\
\hline TRP4 & -256 & taagttatgActAAtaTTaTt & -236 \\
\hline HIS4 & -236 & ggtAAATTagTtAattaatt & -216 \\
\hline CONSENSUS & & ANNAAATTTNTNAA & \\
\hline
\end{tabular}

Figure 7. A comparison of potential $\mathrm{PHO} 4$ and $\mathrm{PHO} 2$ binding sites within the PHO81 promoter with known PHO4 and PHO2 binding sites from PHO5 (10), PHO8 (31), TRP4 (15) and HIS4 (13). Those nucleotides which match the consensus sequence are shown in upper case letters. Nucleotides are numbered such that +1 is the first nucleotide of the first codon.

strain. To examine this possibility, we placed the PHO80 and PHO85 genes under the control of the GAL1 promoter and transformed two strains containing a constitutive mutation in PHO81 (change at amino acid 4 or 147) with plasmids bearing these constructs. In both strains the effect was the same. That is, overexpression of PHO85 had no affect on acid phosphatase activity while overexpression of PHO80 was able to partially repress the constitutive phenotype (results from strain CY81-C12 shown in Figure 6). This indicates that PHO81 may act on PHO80 or that both of these proteins compete for the same target. Still, other possibilities may exist.

\section{DISCUSSION}

We have cloned the PHO81 gene and sequenced its promoter. A homology search indicates that there are several potential PHO4 and $\mathrm{PHO} 2$ binding sites within the promoter (Figures $2 \& 7$ ). The potential PHO4 binding site at -349 to -337 is more homologous to known PHO4 binding sites than the one at -239 to -228 in that it contains the core element, CACGT, shown to be important by others $(10,31)$. Gel shift assays demonstrate that PHO4 binds a fragment containing sequences -349 to -337 but does not bind sequences -239 to -228 in vitro (Creasy et al. manuscript in preparation). Sequences important for PHO2 binding are less well conserved; they are merely characterized as a cluster of $\mathrm{A} \& \mathrm{~T}$ residues $(10,13-15)$. Construction of a PHO81-LacZ fusion allowed the examination of PHO81 expression in repressed and derepressed conditions as well as a variety of genetic backgrounds. While this fusion responded to $P_{i}$ levels, the level of induction is lower than that observed by northern analysis. However, consistent with previous northern analysis, $\mathrm{PHO} 4$ and $\mathrm{PHO} 2$ are required for $\mathrm{PHO} 81$ expression 
as well as the PHO81 molecule itself (20). In addition, the lack of a functional PHO80 or PHO85 molecule causes full derepression of PHO81 expression under high $\mathrm{P}_{\mathrm{i}}$ growth conditions and the level of PHO81 expression in either the strain containing the pho 80 or pho 85 null allele is significantly higher than the level seen in a wild type cell grown under low Pi growth conditions, consistent with previous results seen with acid phosphatase levels in the same strains $(28,32)$. This observation further supports the role of PHO81 as the signal acceptor because PHO81 is the only regulatory factor in this system regulated by inorganic phosphate levels.

To study the mechanism by which PHO81 functions, we have isolated several dominant constitutive mutants in PHO81. Seven independent mutants have been isolated and each found to contain a single base pair change. In total, three amino acids are affected. Examination of PHO81 mRNA levels in two of the mutants indicates that both have increased PHO81 expression, as compared to wild type, in high $\mathrm{P}_{\mathrm{i}}$ growth conditions, but both still respond to $P_{i}$ levels as indicated by an increase in expression in low $\mathrm{P}_{\mathrm{i}}$ growth conditions. Table 2 indicates that the PHO81 gene product is required for its own expression. Thus in the strains containing the constitutive alleles of PHO81, the increased levels of PHO81 mRNA is most likely due to the action of the altered PHO81 gene product increasing transcription from its own promoter. However, the molecular mechanisms responsible for the increased transcription is not known.

Because disruption of the PHO81 gene results in a nonderepressible phenotype, the PHO81 constitutive mutants described here must be gain of function mutations. There are several possibilities for the mode of action of the constitutive PHO81 alleles. The mutations may affect the amount of protein, directly, through an increase in protein stability or mRNA translation, or indirectly, through an increase in mRNA stability. Support for this possibility comes from the observation that expression of a PHO81-LacZ fusion containing a mutation at amino acid 4 had approximately 2-fold higher levels of expression than that of the wild type fusion. Since this fusion does not produce a functional PHO81 protein, we believe that the mutation in the altered allele does not increase the ability of PHO81 to function, but rather increases its effective concentration. The observation that overexpression of wild type PHO81 causes constitutive synthesis of acid phosphatase expression suggests that merely increasing the amount of PHO81 will cause constitutive synthesis of acid phosphatase. Examination of a PHO81-LacZ fusion containing the mutation at amino acid 147 suggests that mutations more internal to the PHO81 protein probably do not affect protein stability but rather, alter the structure of the PHO81 molecule such that the ability of PHO81 to function increases, possibly by increasing the affinity of PHO81 for its target.

The observation that overexpression of PHO80 in a PHO81 constitutive allele was able to partially repress the mutant phenotype, together with the expression studies supports at least two models for the mode of action of the PHO81 gene product, but other possibilities may exist. In both models, under high $\mathrm{Pi}$ growth conditions very little PHO81 is present, and it is in an inactive state. But when inorganic phosphate levels are limiting, PHO81 is activated. In the first model, PHO81 interacts with PHO80. This interaction blocks PHO80 action, allowing expression of PHO5 as well as PHO81. With increasing amounts of PHO81, a further increase in PHO5 expression would result. Another model would be one in which PHO81 and PHO80 compete for a target molecule; however, this target can not be PHO2 or PHO4 since yeast strains containing both PHO80 and PHO81 null alleles produce acid phosphatase constitutively (7). The interaction of PHO81 with PHO85 is not suggested since overexpression of the PHO85 molecule had no affect on acid phosphatase expression in a PHO81 constitutive allele. The models, for PHO85 action, suggested by Madden $e$ al., in which either PHO80 is the target of PHO85 phosphorylation or PHO80 targets another molecule for phosphorylation by PHO85, are still supported. (32). The belief that PHO81 is held in an inactive state is supported since in the presence of cyclohexamide derepression of PHO5 expression occurs (6). However, the manner by which PHO81 is held in an inactive state is still not known, but this inactivation could be due to a reversible modification, sub-cellular localization or the presence of a small signal molecule. Work is now underway to elucidate the interactions between the regulatory proteins involved in this system.

\section{ACKNOWLEDGMENTS}

We thank M.Johnston and P.Hieter for yeast strains and plasmids and David McGonagle and David Fleisher for technical assistance. This work was supported by grant, GM41620, from the National Institutes of Health.

\section{REFERENCES}

1. Bajwa, W., Meyhack, B., Rudolph, H., Schweingruber, A. and Hinnen, A. (1984) Nucl. Acids Res., 12, 7721-7739.

2. Hinnen,A., Bajwa, W., Meyhack, B. and Rudolph, H. (1987) In,TorrianiGorini, A., Rothman, F. G., Silver, S, Wright, A. and Yagil, E. (eds.), Phosphate metabolism and cellular regulation in microorganisms, American Society for Microbiology, Washington, D. C.,p. 56-62.

3. Venter, U. and Horz, W. (1989) Nucl. Acids Res. 17, 1353-1369.

4. Rogers, D. T., Lemire, J. M., and Bostian, K. A. (1982) Proc. Natl. Acad. Sci. USA 79, 2157-2161.

5. Kramer, R. A. and Andersen, N. (1980) Proc. Natl. Acad. Sci. 77, $6541-6545$.

6. Lemire, J. M., Willcock, T., Halvorson, H. O., and Bostian, K. A. (1985) Mol. Cell. Biol. 5, 2131-2141.

7. Toh-e, A., Ueda, Y., Kakimoto, S-I. and Oshima, Y. (1973). Isolation and characterization of acid phosphatase mutants in Saccharomyces cerevisiae. J. Bacteriol. 113, 727-738.

8. Toh-e A. and Oshima, Y. (1974) J. Bacteriol.120, 608-817.

9. Ueda, Y., Toh-e, A. and Oshima, Y. (1975) J. Bacteriol. 122, 911-922.

10. Vogel, K., Horz, W. and Hinnen, A. (1989) Mol. Cell. Biol. 9, 2050-2057.

11. Ogawa, N., and Oshima, Y. (1990) Mol. Cell. Biol. 10, 2224-2236.

12. Burglin, T. R. (1988) Cell 53, 339-340.

13. Ardnt, K. T. Styles, C. and Fink, G. R. (1987) Science 237, 874-880.

14. Senstag, C. and Hinnen, A. (1988) Gene 67, 223-228.

15. Braus, G., Mosch, H-U., Vogel, K., Hinnen, A. and Hutter, R. (1989) EMBO J. 8, 939-945.

16. Oshima, Y. (1982). In, Strathern, J. N., Jones, E. W. and Broach, J. R. (eds.), The Molecular Biology of the Yeast Saccharomyces, Cold Spring Harbor Laboratory Cold Spring Harbor, N.Y. VolII, 159-180.

17. Uesono, Y., Tanaka, K. and Toh-e A. (1987) Nucl. Acids Res. 15, 10299- 10309.

18. Toh-e, A., Tanaka, K., Uesono, Y. and Wickner, R. B. (1988) Mol. Gen. Genet. 214, 162-164.

19. Uesono, Y., Tokai, M., Tanaka, K. and Toh-e A. (1992) MGG $231,426-432$.

20. Yoshida, K., Ogawa, N. and Oshima, Y. (1989) MGG 217, 40-46.

21. Coche, T., Prozzi, D. Legrain, M., Hilger, F.and Vandenhaute, J. (1990) Nucl. Acids Res. 18, 2176.

22. Ito, H., Fukada, Y., Murata, K. and Kimura, A. (1983) J. Bacteriol. 153, 163-171.

23. Johnston, M. (1986) Genetics 120, 63-74. 
1982 Nucleic Acids Research, 1993, Vol. 21, No. 8

24. Johnston, M., and Davis, R. W. (1984) Mol. Cell. Biol. 4, 1440-1448.

25. Innis, M. A. and Gelfand, D. H. (1990) In, Innis, M. A., Gelfand, D. H., Sninsky, J. J. and White, T. J. (eds.), PCR Protocols: A guide to methods \& applications, Acedemic Press, Inc., San Diego, CA, 3-12.

26. Rose, M. D., Novick, P., Thomas, J. H., Botstein, D. and Fink, G. R. (1987) Gene 60, 237-243.

27. Sikorski, R. S. and Hieter, P. (1989) Genetics 122, 19-27.

28. Madden, S. L., Creasy, C. L., Srinivas, V. Fawcett, W. and Bergman, L. W. (1988) Nucl. Acids Res. 16, 2625-2637.

29. Myers, A. M. Tzagoloff, A. Kinney, D. M. and Lusty, C. J. (1986) Gene 41, 299-310.

30. Bergman, L. W. (1986) Mol. Cell. Biol. 6, 2298-2304.

31. Hayashi, N. and Oshima, Y. (1991) Mol. Cell. Biol. 11, 785-794.

32. Madden, S. L., Johnson, D. L. and Bergman, L. W. (1990) Mol. Cell. Biol. 10, 5950-5957. 